\title{
Relationship between lower limb position and pelvic floor muscle surface electromyography activity in menopausal women: a prospective observational study
}

\author{
This article was published in the following Dove Press journal: \\ Clinical Interventions in Aging \\ 4 January 2017 \\ Number of times this article has been viewed
}

\author{
Tomasz Halski' \\ Kuba Ptaszkowski \\ Lucyna Słupska' \\ Robert Dymarek ${ }^{3}$ \\ Małgorzata Paprocka- \\ Borowicz ${ }^{2}$ \\ 'Department of Physiotherapy, \\ Opole Medical School, Opole, \\ ${ }^{2}$ Department of Clinical Biomechanics \\ and Physiotherapy in Motor System \\ Disorders, ${ }^{3}$ Department of Nervous \\ System Diseases, Faculty of Health \\ Science, Wroclaw Medical University, \\ Wroclaw, Poland
}

\begin{abstract}
Objectives: In physiotherapeutic practice, special attention is being given to the reciprocal anatomical, physiological, and biomechanical relationship of the pelvis and the structures connected to it. However, the scientific literature shows mainly the theoretical information about their mutual connections. The lack of information about these relations from a practical aspect coupled with the paucity of scientific papers on the impact of posture changes on the pelvic floor led the authors to conduct this study. The primary aim of this study was to compare the resting and functional bioelectrical activities of pelvic floor muscles (PFMs) depending on three different positions of the lower limbs (positions A, B, and C) in the supine position.
\end{abstract}

Materials and methods: This was a prospective observational study evaluating resting and functional activities of the PFM depending on the position of the lower limbs. The study was carried out at the Department and Clinic of Urology, University Hospital in Wroclaw, Poland and the target group were women in the menopausal period. Bioelectrical activity of PFM was recorded using a surface electromyographic instrument in the supine position. Results of the values obtained in A, B, and C positions were compared using a one-way analysis of variance.

Results: In position A, the average resting surface electromyography (sEMG) activity of PFM was $6.9 \pm 2.6 \mu \mathrm{V}$; in position $\mathrm{B}$, the result was $6.9 \pm 2.5 \mu \mathrm{V}$ and in position $\mathrm{C}$, the resting sEMG activity was $5.7 \pm 1.8 \mu \mathrm{V}(P=0.0102)$. The results of the functional bioelectrical activity of PFM were as follows: position $\mathrm{A}-20.3 \pm 11.8 \mu \mathrm{V}$, position $\mathrm{B}-19.9 \pm 10.6 \mu \mathrm{V}$, and position $\mathrm{C}-25.3 \pm 10.9 \mu \mathrm{V}(P=0.0104)$.

Conclusion: The results showed that in the supine position, the PFM achieved the lowest resting activity and the highest functional activity. Therefore, the supine position can be recommended for the diagnosis and therapy of weakened PFM.

Keywords: pelvic floor muscles, menopause, surface electromyography, synergistic muscle

\section{Introduction}

Stress urinary incontinence (SUI), pelvic organ prolapse, and chronic pelvic pain are frequent complaints of women in perimenopause and menopause and result mainly from pelvic floor insufficiency. Proper statics of the pelvic floor provides adequate support for the urethra and bladder, which determines the correct mechanism of continence. Anatomical disorders such as loss of support for the bladder base and the proximal urethra are a direct cause of SUI. ${ }^{1-3}$ Women diagnosed with SUI demonstrated changed configuration of these structures as well as disorders in their functioning. Among the
Correspondence: Tomasz Halski Department of Physiotherapy, Opole Medical School, Katowicka 68, 45-060 Opole, Poland Tel +48 774423524 Fax +48 774423517 Email tomhalski@wp.pl (c)
hereby accept the Terms. Non-commercial uses of the work are permitted without any further permission from Dove Medical Press Limited, provided the work is properly attributed. For permission hereby accept the Terms. Non-commercial uses of the work are permitted without any further permission from Dove Medical Press Limited, provided the work is properly attributed. For permissio 
causes of these changes are the weakening of connective tissue structures and the loosening of connections within the pelvic floor. ${ }^{4-7}$ It is believed that the menopause plays the most significant role in this pathogenesis. Symptoms related to the urogenital system may affect $50 \%$ of women in this period..$^{3,8-13}$ Many authors ${ }^{3,9,12,14-17}$ indicate a decreased level of estrogens as the main cause of the symptoms. One of the key roles of estrogens, which may be impaired during menopause, is their influence on the synthesis and metabolism of collagen, eg, within the lower urinary tract, and on the increase in the number of muscle fibers of the detrusor muscle as well as other muscles comprising the pelvic floor., ${ }^{3,14-16}$ During the menopause, a reduced number of estrogen receptors in the epithelia of the urethra, bladder triangle, or vaginal mucosa can be observed. This decrease is also seen in the structures supporting the pelvic organs, eg, uterosacral ligament, levator ani muscle, and pubocervical fascia. ${ }^{11,15,18-21}$

The other cause of disorders in the statics of the pelvic floor is damage to the muscle and connective tissue structures due to vaginal deliveries. ${ }^{11,22-24}$ Botelho et $\mathrm{al}^{24}$ reported a significant loss of muscle contractility during electromyography (EMG) evaluation in women who underwent vaginal delivery. In patients who had undergone cesarean section, a decrease in muscle function was not observed. Another significant factor increasing the risk of severe perineal trauma is an episiotomy. It should be stated that despite many studies on the negative impact of episiotomy on the pelvic floor, in many countries, it is still a routine practice. A study conducted by Blondel et $\mathrm{al}^{25}$ based on the Euro-Peristat Project demonstrated that many European countries had episiotomy rates $>60 \%$ (Poland $67.5 \%$, Romania 68.2\%, Portugal 72.9\%, and Cyprus 75\%).

Recent randomized clinical trials have shown that currently the most comprehensive therapeutic procedure in SUI are properly chosen and properly executed pelvic floor muscle (PFM) exercises along with the use of objective, minimally invasive and safe diagnostic methods (eg, EMG). ${ }^{24,26,27}$ In physiotherapeutic practice, special attention is being given to the reciprocal anatomical, physiological, and biomechanical relationship of the pelvis and the structures connected to it. However, the scientific literature ${ }^{6,7,28-33}$ shows mainly theoretical information about their mutual connections.

The lack of information about these relations from the practical aspect as well as the paucity of scientific papers $^{31,33-35}$ on the impact of posture changes on the pelvic floor and the function of the lower urinary tract prompted this study. The authors attempted to answer the question of whether the position of the lower limbs, affecting the different orientations of the pelvis, can influence PFM activity.

\section{Aim}

The primary aim of this study was to compare the resting and functional bioelectrical activities of PFM depending on three different positions of the lower limbs (position A, B, C) in the supine position. The secondary goal was to compare the surface electromyography (sEMG) activity of selected synergists of the PFM, eg, adductor magnus (AM), rectus abdominis (RA), and gluteus maximus (GM; two sides: left and right), in different positions of the lower limbs in the supine position as well as to determine the relationship between the myoelectric activity of the PFM and synergist muscles.

\section{Materials and methods}

This was a prospective, cross-sectional observational study evaluating resting and functional activities of the PFM depending on the position of the lower limbs in menopausal women. The presented study is a part of the research project funded by the National Science Centre in the "Preludium" call on the basis of the decision number DEC - 2011/03/N/ NZ7/00505. The study was approved by the Bioethics Committee of the Wroclaw Medical University on 5 July 2012 with the approval number KB - 611/2012. Moreover, the study was registered at the Australian New Zealand Clinical Trials Registry platform (ACTRN1261300114470736) as a prospective observational study.

The study was carried out at the Department and Clinic of Urology of University Hospital in Wroclaw between December 2012 and December 2014.

The target group were women in the menopausal period. All recruited women were subjected to evaluation by the inclusion and exclusion criteria in order to qualify for the appropriate study group. The inclusion criteria assumed in the study included written informed consent, doctor's and/ or physiotherapist's permission to participate in the study, the overall well-being on the day of examination and no contraindications for the sEMG measurements. The exclusion criteria included age older than 75 years; no history of menopause; gynecological surgery - surgery in the abdomen, pelvis, and lower extremities - in the last 10 years; injuries to the lower extremities, pelvis or, spine on the examination day; contraindications for measurements - infection, menstruation, and allergies to nickel; the occurrence of pain during the examination and withdrawing during the examination.

The visit protocol with the participants included an interview, instruction on the purpose of measurement and testing procedures and sEMG measurement of the PFMs and their synergists in three positions of lower limbs. The measurements were performed with the lower limbs in three different 
positions (Figure 1): position A (position of lower limbs in $90^{\circ}$ of flexion in hip and knee joints; the limbs were placed freely on adequately profiled wedges - decreased anterior pelvic tilt), position B (position of lower limbs with a slight flexion of hip and knee joints; intermediate pelvic position) and position $\mathrm{C}$ (supine position; lower limbs without flexion in hip and knee joints and upper limbs resting freely on the couch - increased anterior pelvic tilt).

The order of the positions was established randomly for each participant by the Random Integer Generator (www. random.org).

The participants, after setting the pelvis in a particular position, made five 5-second maximal contractions of the PFM (functional sEMG activity) with a 5-second rest between contractions (resting sEMG activity). The rest between measurements in the consecutive position was 60 seconds.

The resting and functional bioelectric activities were measured using the MyoSystem 1400L (Noraxon, Scottsdale, AZ, USA) with eight channels, along with the surface and endovaginal electrodes. The specification of the device fulfills the requirements set out in ISEK (International Society of Electrophysiology and Kinesiology) and SENIAM (Surface ElectroMyoGraphy for the Non-Invasive Assessment of Muscle) publications. The equipment for recording bioelectric

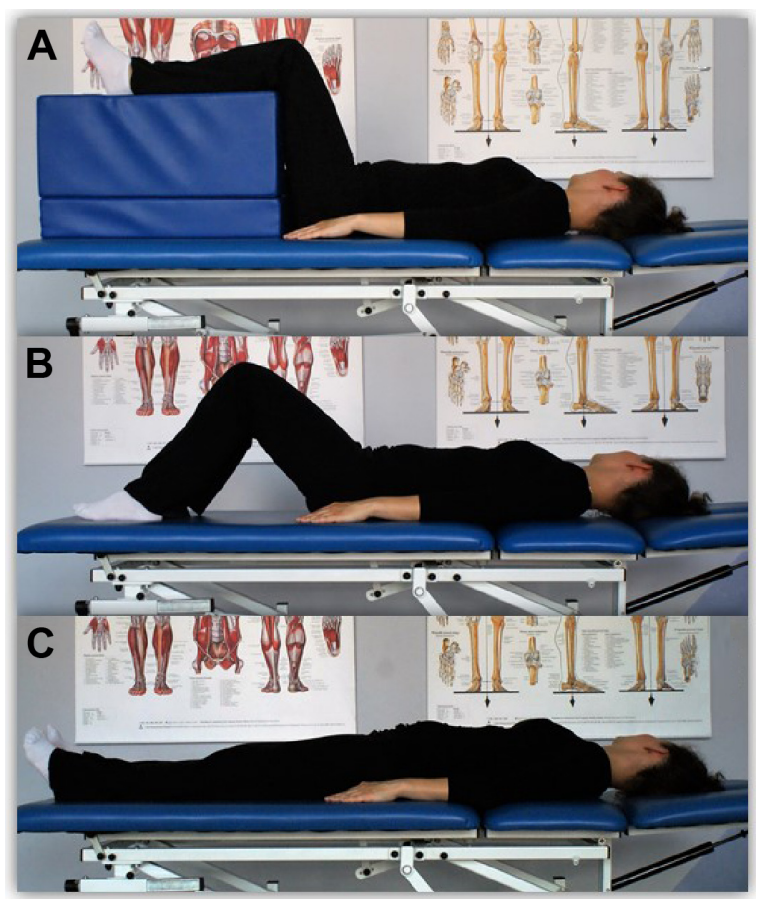

Figure I Three different positions of lower limbs used during the measurements. Notes: (A) Position A: position of lower limbs in $90^{\circ}$ of flexion in hip and knee joints - decreased anterior pelvic tilt. (B) Position B: position of lower limbs with a slight flexion of hip and knee joints - intermediate pelvic position. (C) Position C: supine position (lower limbs without flexion in hip and knee joints) - increased anterior pelvic tilt. potentials includes main unit with a built-in analog to digital converter (ADC) card; signal amplifiers and preamplifiers; a computer with MyoResearch XP Master Edition software, version 1.04; compatible surface and vaginal electrodes. The measuring set was characterized with the sEMG recording frequency in the range of 10-450 Hz. The frequency range for the amplifier was $10 \mathrm{~Hz}$ for high-pass cutoff, with the $500 \mathrm{~Hz}$ filter for the low-pass cutoff. The level of common mode rejection amounted to a minimum of $100 \mathrm{~dB}$, and input impedance for EMG channels was $>100 \mathrm{M} \Omega$. The system was characterized by the high sensitivity of the recorded EMG signal $-1 \mu \mathrm{V}$. To record the sEMG signal from the PFM, a pear-shaped endovaginal electrode Life-Care Vaginal Probe PR-02 (Everyway Medical Instruments Co., Ltd., New Taipei City, Taiwan) was used.

The physical examination was conducted with the use of standardized assessment scales for menopause and the symptoms of urinary incontinence. Menopause Rating Scale (MRS) was used to evaluate the symptoms of menopause.

Statistical analysis was performed using Statistica 12 (StatSoft, Inc., Tulsa, OK, USA) under the license of the Medical University in Wroclaw. For the measurable variables, the arithmetic mean, standard deviation (SD) and extreme values were calculated. All quantitative variables were tested with the Shapiro-Wilk test to determine the type of distribution. Comparisons of results between the values obtained in the $\mathrm{A}, \mathrm{B}$, and $\mathrm{C}$ positions were performed using a parametric test, one-way analysis of variance (ANOVA) along with post hoc testing (Tukey's test) or the nonparametric ANOVA Kruskal-Wallis analysis and multiple comparisons of mean ranks, depending on the fulfillment of the test assumptions. A multivariate linear regression analysis was used to assess relationships between the bioelectrical activity of PFM and bioelectrical activity of all tested synergists (AM, RA, GM - left and right sides). For all comparisons, a level of $\alpha=0.05$ was assumed, and the obtained $P$-values were rounded to four decimal places.

\section{Results}

\section{Characteristics of the study group}

A total of 55 women, aged between 50 and 75 years ( $\overline{\mathrm{x}}=64.9$ years; $\mathrm{SD}=5.3$ years), participated in the study. The characteristics of the group are presented in Table 1. All women underwent the menopause between 40 and 60 years of age $(\overline{\mathrm{x}}=50.7$ years; $\mathrm{SD}=5.0$ years $)$. Each participant in the MRS questionnaire reported symptoms typical for the menopause and postmenopause periods. The results of the MRS questionnaire ranged between 1 and 23 points $(\overline{\mathrm{x}}=10.9$ points; $\mathrm{SD}=5.7$ points). 
Table I The characteristics of the study group

\begin{tabular}{llllll}
\hline Characteristics & $\mathbf{n}$ & $\overline{\mathbf{x}}$ & Min & Max & SD \\
\hline Age (years) & 55 & 64.9 & 50.0 & 75.0 & 5.3 \\
Weight $(\mathrm{kg})$ & 55 & 66.8 & 50.0 & 92.0 & 10.2 \\
Height $(\mathrm{m})$ & 55 & 1.61 & 1.47 & 1.72 & 0.05 \\
BMI $\left(\mathrm{kg} / \mathrm{m}^{2}\right)$ & 55 & 25.7 & 18.8 & 35.3 & 3.9 \\
Number of births & 55 & 1.5 & 0.0 & 3.0 & 0.9 \\
Menopausal age (years) & 55 & 50.7 & 40.0 & 60.0 & 5.0 \\
Total score of the MRS & 55 & 10.9 & 1.0 & 23.0 & 5.7 \\
\hline
\end{tabular}

Abbreviations: $n$, number of participants; $\bar{x}$, mean; Min, minimum; Max, maximum; SD, standard deviation; BMI, body mass index; MRS, Menopause Rating Scale.

\section{Primary result}

In position $\mathrm{A}$, the average resting sEMG activity of the PFM was $6.9 \mu \mathrm{V}$ (min-max: $3.3-15.3 \mu \mathrm{V}$; $\mathrm{SD}=2.6 \mu \mathrm{V})$; in position $\mathrm{B}$ also, the result was $6.9 \mu \mathrm{V}$ (min-max: $3.0-14.8 \mu \mathrm{V}$; $\mathrm{SD}=2.5 \mu \mathrm{V}$ ); and in position $\mathrm{C}$, the resting sEMG activity was $5.7 \mu \mathrm{V}$ (min-max: $2.6-11.7 \mu \mathrm{V}$; $\mathrm{SD}=1.8 \mu \mathrm{V})$. The results differed significantly ( $P=0.0102$; Figure 2$)$.

The results of the functional bioelectrical activity of the PFM were as follows: position $\mathrm{A}-20.3 \mu \mathrm{V}$ (min-max: 4.5-55.1 $\mu \mathrm{V} ; \mathrm{SD}=11.8 \mu \mathrm{V})$, position $\mathrm{B}-19.9 \mu \mathrm{V}$ (min$\max : 5.8-48.2 \mu \mathrm{V} ; \mathrm{SD}=10.6 \mu \mathrm{V})$, and position $\mathrm{C}-25.3 \mu \mathrm{V}$ (min-max: $10.0-63.8 \mu \mathrm{V}$; SD $=10.9 \mu \mathrm{V}$ ). The differences were statistically significant $(P=0.0104$; Figure 3$)$.

\section{Secondary result}

The highest bioelectrical potential of AM (left and right sides), both during the resting and functional activities of the PFM,

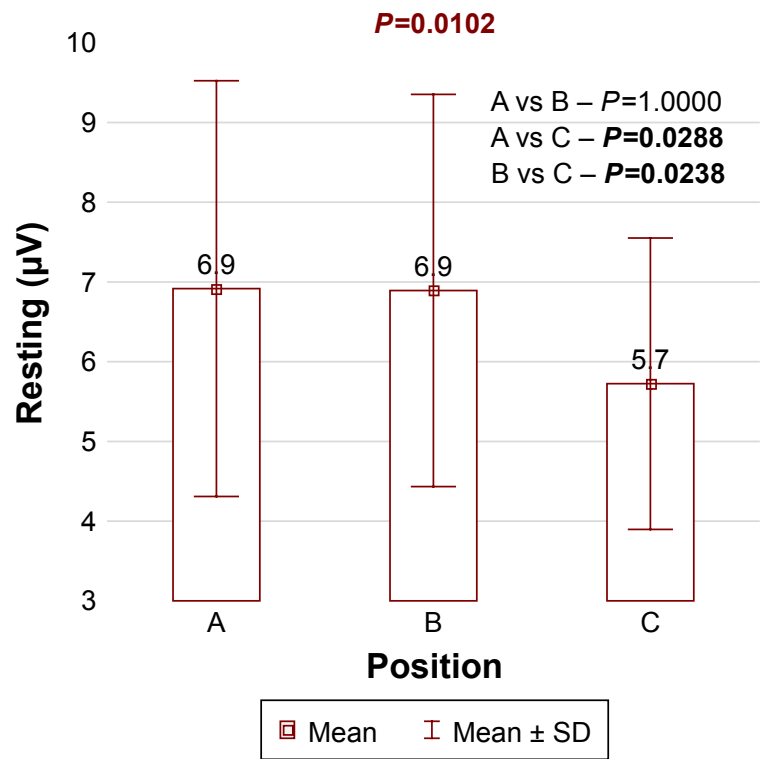

Figure 2 The comparison of the resting bioelectrical activity of PFM obtained in the three studied positions: $\mathrm{A}, \mathrm{B}$, and $\mathrm{C}$.

Notes: Position A: position of lower limbs in $90^{\circ}$ of flexion in hip and knee joints decreased anterior pelvic tilt. Position B: position of lower limbs with a slight flexion of hip and knee joints - intermediate pelvic position. Position C: supine position (lower limbs without flexion in hip and knee joints) - increased anterior pelvic tilt. Bold values are statistically significant $(P<0.05)$.

Abbreviations: PFM, pelvic floor muscle; SD, standard deviation.

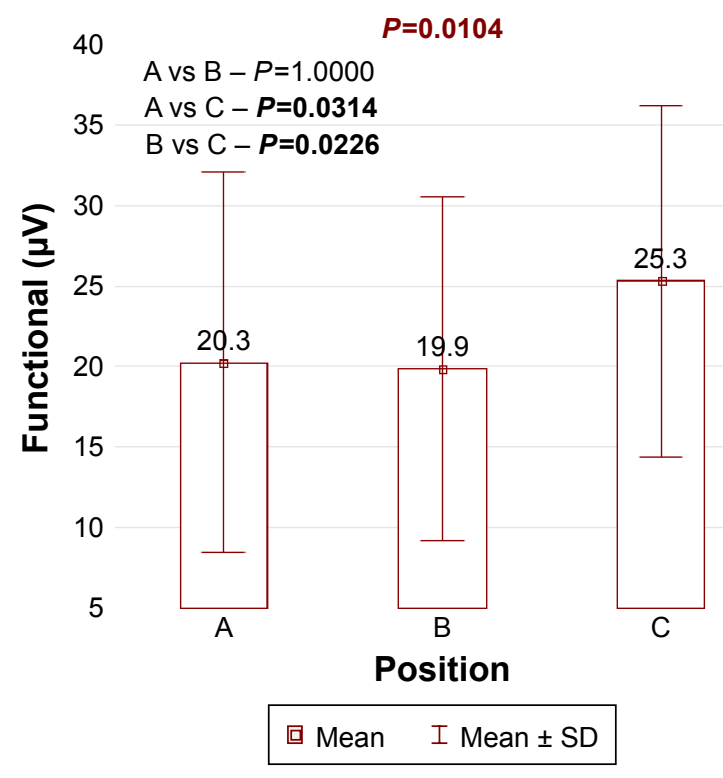

Figure 3 Comparison of the functional bioelectrical activity of PFM obtained in the three studied positions: A, B, and C.

Notes: Position A: position of lower limbs in $90^{\circ}$ of flexion in hip and knee joints decreased anterior pelvic tilt. Position B: position of lower limbs with a slight flexion of hip and knee joints - intermediate pelvic position. Position C: supine position (lower limbs without flexion in hip and knee joints) - increased anterior pelvic tilt. Bold values are statistically significant $(P<0.05)$.

Abbreviations: PFM, pelvic floor muscle; SD, standard deviation.

was obtained in position B. In the case of RA sEMG activity, there were no statistically significant differences between the results obtained in all positions. The highest sEMG of the GM (on the right side) during the resting and functional activities of the PFM was observed in positions A and B. On the left side, there were no statistically significant differences between positions. The results are shown in Tables 2-4.

Multivariate linear regression did not find any association between the resting bioelectrical activity of the PFM and the bioelectrical activity of all synergist muscles in each position (Table 5). Similar results were registered taking into account the functional bioelectrical activity of the PFM (Table 6).

\section{Discussion}

The primary aim of the study was to compare the resting and functional bioelectrical activities of PFM in different positions. It was shown that in the supine position (C), the resting sEMG activity of the PFM reached the lowest values $(5.7 \mu \mathrm{V})$. Both in the position with lower limbs placed on wedges (A) and with lower limbs slightly bent (B), the resting activity achieved the same values $(6.9 \mu \mathrm{V})$. The results confirm the use of the supine position as the most conducive to PFM relaxation. It would seem that this phenomenon may indirectly result from the relaxation of synergist muscles, especially the AM and GM (in the supine position, their insertions are relatively close, which contributes to lower resting 
Table 2 The comparison of sEMG activity of AM (left and right sides) registered in A, B, and C positions during the resting and functional PFM activities

\begin{tabular}{|c|c|c|c|c|c|c|c|c|c|c|}
\hline $\begin{array}{l}\text { Bioelectrical } \\
\text { activity of muscle }\end{array}$ & Side & $\begin{array}{l}\text { PFM bioelectrical } \\
\text { activity }\end{array}$ & Position & $\mathbf{n}$ & $\overline{\mathbf{x}}$ & Min & Max & SD & $\begin{array}{l}P \text {-value } \\
\text { (main effect) }\end{array}$ & $\begin{array}{l}P \text {-value (post } \\
\text { hoc analysis) }\end{array}$ \\
\hline \multirow[t]{12}{*}{ AM muscle $(\mu \mathrm{V})$} & Right & Resting & A & 55 & 4.1 & 2.2 & 9.7 & 1.2 & 0.0000 & $A: B=0.0000$ \\
\hline & & & B & 55 & 8.7 & 2.7 & 26.7 & 5.9 & & $A: C=0.7597$ \\
\hline & & & C & 55 & 3.9 & 2.0 & 10.0 & 1.4 & & $\mathrm{~B}: \mathrm{C}=0.0000$ \\
\hline & & Functional & $A$ & 55 & 4.5 & 2.4 & 11.7 & 1.6 & 0.0000 & $A: B=0.0000$ \\
\hline & & & B & 55 & 9.9 & 3.0 & 31.9 & 7.0 & & $\mathrm{~A}: \mathrm{C}=0.7584$ \\
\hline & & & C & 55 & 4.6 & 2.0 & 20.3 & 3.2 & & $\mathrm{~B}: \mathrm{C}=0.0000$ \\
\hline & Left & Resting & A & 55 & 4.5 & 2.5 & 13.4 & 2.0 & 0.0000 & $A: B=0.0000$ \\
\hline & & & B & 55 & 8.5 & 2.6 & 31.9 & 5.9 & & $\mathrm{~A}: \mathrm{C}=0.4018$ \\
\hline & & & C & 55 & 3.9 & 2.4 & 9.2 & 1.2 & & $\mathrm{~B}: \mathrm{C}=0.0000$ \\
\hline & & Functional & $A$ & 55 & 5.3 & 2.7 & 20.2 & 3.3 & 0.0000 & $A: B=0.000 I$ \\
\hline & & & B & 55 & 10.0 & 2.7 & 30.1 & 6.8 & & $A: C=0.2513$ \\
\hline & & & C & 55 & 4.7 & 2.6 & 20.4 & 3.1 & & $\mathrm{~B}: \mathrm{C}=0.0000$ \\
\hline
\end{tabular}

Notes: Position A: position of lower limbs in $90^{\circ}$ of flexion in hip and knee joints - decreased anterior pelvic tilt. Position B: position of lower limbs with a slight flexion of hip and knee joints - intermediate pelvic position. Position C: supine position (lower limbs without flexion in hip and knee joints) - increased anterior pelvic tilt.

Abbreviations: sEMG, surface electromyography; AM, adductor magnus; PFM, pelvic floor muscle; $n$, number of participants; $\bar{x}$, mean; Min, minimum; Max, maximum; $\mathrm{SD}$, standard deviation.

potential), but the authors did not report any association between PFM and the synergists.

The literature reveals only few research studies related to the relationship between posture and the PFM activity. Bø and Finckenhagen ${ }^{37}$ evaluated the strength of PFM in two different positions. They conducted the measurement of resting pressure, maximum squeeze pressure, and holding periods in seconds, both in supine and standing positions. Although they noted significantly higher vaginal resting pressure in the standing position, there were no differences between these two positions in maximal strength and holding time. In the present study, the highest functional sEMG was registered in the supine position $(25.3 \mu \mathrm{V})$. Therefore, it seems that this position is justifiably the most commonly used for both the diagnosis and treatment of SUI. ${ }^{37}$

The relationship between the position and the PFM was also assessed by Chen et al..$^{35}$ They evaluated 39 incontinent women to determine the changes in PFM activity during various pelvic tilt angles created by horizontal, dorsiflexed, and plantar-flexed ankle positions. To change the pelvic tilt angle, an adjustable angle platform to set the ankles in a particular position was used. According to the authors, the horizontal position was the neutral position of the pelvis, the dorsiflexed ankle position facilitated the anterior pelvic tilt, and the plantar-flexed ankle position caused the posterior pelvic tilt. The results of this study showed that higher

Table 3 Comparison of sEMG activity of RA (left and right sides) registered in A, B, and C positions during the resting and functional PFM activities

\begin{tabular}{|c|c|c|c|c|c|c|c|c|c|c|}
\hline $\begin{array}{l}\text { Bioelectrical } \\
\text { activity of muscle }\end{array}$ & Side & $\begin{array}{l}\text { PFM bioelectrical } \\
\text { activity }\end{array}$ & Position & $\mathbf{n}$ & $\overline{\mathbf{x}}$ & Min & Max & SD & $\begin{array}{l}P \text {-value } \\
\text { (main effect) }\end{array}$ & $\begin{array}{l}P \text {-value (post } \\
\text { hoc analysis) }\end{array}$ \\
\hline \multirow[t]{12}{*}{$\overline{\mathrm{RA}}(\mu \mathrm{V})$} & Right & Resting & $A$ & 55 & 4.7 & 2.8 & 8.2 & 1.3 & 0.1114 & $A: B=0.9997$ \\
\hline & & & B & 55 & 4.7 & 2.9 & 8.3 & I.I & & $\mathrm{A}: \mathrm{C}=0.1649$ \\
\hline & & & $C$ & 55 & 5.3 & 2.8 & 16.8 & 2.5 & & $\mathrm{~B}: \mathrm{C}=0.1569$ \\
\hline & & Functional & $A$ & 55 & 4.9 & 2.9 & 8.5 & 1.3 & 0.1846 & $A: B=0.9735$ \\
\hline & & & B & 55 & 5.0 & 2.9 & 8.4 & 1.3 & & $\mathrm{~A}: \mathrm{C}=0.2055$ \\
\hline & & & C & 55 & 5.5 & 2.4 & 16.6 & 2.5 & & $\mathrm{~B}: \mathrm{C}=0.3013$ \\
\hline & Left & Resting & $A$ & 55 & 4.9 & 3.0 & 9.6 & 1.1 & 0.5674 & $A: B=0.8430$ \\
\hline & & & B & 55 & 4.8 & 3.0 & 7.9 & 0.9 & & $\mathrm{~A}: \mathrm{C}=0.8669$ \\
\hline & & & C & 55 & 5.0 & 3.2 & 8.2 & 1.1 & & $\mathrm{~B}: \mathrm{C}=0.5352$ \\
\hline & & Functional & A & 55 & 5.0 & 3.0 & 7.5 & 1.0 & 0.7744 & $A: B=0.9972$ \\
\hline & & & B & 55 & 5.1 & 3.0 & 7.8 & 1.1 & & $\mathrm{~A}: \mathrm{C}=0.7909$ \\
\hline & & & C & 55 & 5.2 & 3.2 & 8.0 & 1.0 & & $\mathrm{~B}: \mathrm{C}=0.8305$ \\
\hline
\end{tabular}

Notes: Position A: position of lower limbs in $90^{\circ}$ of flexion in hip and knee joints - decreased anterior pelvic tilt. Position B: position of lower limbs with a slight flexion of hip and knee joints - intermediate pelvic position. Position C: supine position (lower limbs without flexion in hip and knee joints) - increased anterior pelvic tilt.

Abbreviations: sEMG, surface electromyography; RA, rectus abdominis; PFM, pelvic floor muscle; $n$, number of participants; $\bar{x}$, mean; Min, minimum; Max, maximum; $\mathrm{SD}$, standard deviation. 
Table 4 The comparison of sEMG activity of GM (left and right sides) registered in $\mathrm{A}$, B, and $\mathrm{C}$ positions during the resting and functional PFM activities

\begin{tabular}{|c|c|c|c|c|c|c|c|c|c|c|}
\hline $\begin{array}{l}\text { Bioelectrical } \\
\text { activity of muscle }\end{array}$ & Side & $\begin{array}{l}\text { PFM bioelectrical } \\
\text { activity }\end{array}$ & Position & $\mathbf{n}$ & $\overline{\mathbf{x}}$ & Min & Max & SD & $\begin{array}{l}P \text {-value } \\
\text { (main effect) }\end{array}$ & $\begin{array}{l}P \text {-value (post } \\
\text { hoc analysis) }\end{array}$ \\
\hline \multirow[t]{12}{*}{$\mathrm{GM}(\mu \mathrm{V})$} & Right & Resting & $A$ & 55 & 4.6 & 2.2 & 25.6 & 3.7 & 0.0392 & $A: B=0.9065$ \\
\hline & & & B & 55 & 4.7 & 2.1 & 24.6 & 3.7 & & $\mathrm{~A}: \mathrm{C}=0.4018$ \\
\hline & & & C & 55 & 3.9 & 2.0 & 24.8 & 3.2 & & $\mathrm{~B}: \mathrm{C}=0.0342$ \\
\hline & & Functional & $A$ & 55 & 5.4 & 2.1 & 28.4 & 4.9 & 0.0109 & $A: B=1.0000$ \\
\hline & & & B & 55 & 5.8 & 2.0 & 36.1 & 5.6 & & $\mathrm{~A}: \mathrm{C}=0.0685$ \\
\hline & & & C & 55 & 4.3 & 2.0 & 24.8 & 3.3 & & $\mathrm{~B}: \mathrm{C}=0.0135$ \\
\hline & Left & Resting & $A$ & 55 & 3.6 & 2.5 & 21.2 & 2.5 & 0.0799 & $A: B=0.5534$ \\
\hline & & & B & 55 & 3.8 & 2.6 & 22.1 & 2.6 & & $\mathrm{~A}: \mathrm{C}=1.0000$ \\
\hline & & & C & 55 & 3.6 & 2.6 & 24.7 & 2.9 & & $\mathrm{~B}: \mathrm{C}=0.0762$ \\
\hline & & Functional & $A$ & 55 & 4.8 & 2.5 & 27.0 & 4.3 & 0.1373 & $A: B=1.0000$ \\
\hline & & & B & 55 & 4.9 & 2.5 & 34.5 & 5.0 & & $\mathrm{~A}: \mathrm{C}=0.7135$ \\
\hline & & & C & 55 & 4.1 & 2.6 & 24.6 & 3.4 & & $\mathrm{~B}: \mathrm{C}=0.1429$ \\
\hline
\end{tabular}

Notes: Position A: position of lower limbs in $90^{\circ}$ of flexion in hip and knee joints - decreased anterior pelvic tilt. Position B: position of lower limbs with a slight flexion of hip and knee joints - intermediate pelvic position. Position C: supine position (lower limbs without flexion in hip and knee joints) - increased anterior pelvic tilt.

Abbreviations: sEMG, surface electromyography; GM, gluteus maximus; PFM, pelvic floor muscle; $n$, number of participants; $\bar{x}$, mean; Min, minimum; Max, maximum; SD, standard deviation.

Table 5 Results of the multiple linear regression of the resting bioelectrical activity of PFM in positions A, B, and C

\begin{tabular}{|c|c|c|c|c|c|c|c|c|c|c|c|c|}
\hline \multirow{3}{*}{$\begin{array}{l}\text { Bioelectrical } \\
\text { activity of } \\
\text { muscle }\end{array}$} & \multicolumn{12}{|c|}{ Resting bioelectrical activity of PFM in position } \\
\hline & \multicolumn{4}{|l|}{$\bar{A}$} & \multicolumn{4}{|l|}{ B } & \multicolumn{4}{|l|}{ C } \\
\hline & $\bar{\beta}$ & $P$-value & $-95 \% \mathrm{Cl}$ & $+95 \% \mathrm{Cl}$ & $\bar{\beta}$ & $P$-value & $-95 \% \mathrm{Cl}$ & $+95 \% \mathrm{Cl}$ & $\beta$ & $P$-value & $-95 \% \mathrm{Cl}$ & $+95 \% \mathrm{Cl}$ \\
\hline AM (right) & 0.14 & 0.3569 & -0.35 & 0.95 & 0.17 & 0.3592 & -0.08 & 0.23 & 0.12 & 0.4331 & -0.23 & 0.53 \\
\hline AM (left) & 0.24 & 0.2380 & -0.21 & 0.83 & 0.04 & 0.8379 & -0.15 & 0.18 & 0.18 & 0.3214 & 0.19 & 0.64 \\
\hline RA (right) & -0.09 & 0.6183 & -0.95 & 0.57 & -0.14 & 0.4151 & -1.05 & 0.44 & -0.29 & 0.0754 & -0.45 & 0.02 \\
\hline RA (left) & -0.03 & 0.8839 & -0.91 & 0.78 & -0.12 & 0.4765 & -1.20 & 0.57 & -0.03 & 0.8366 & -0.55 & 0.44 \\
\hline GM (right) & 0.09 & 0.5699 & -0.17 & 0.30 & 0.09 & 0.6500 & -0.20 & 0.32 & 0.10 & 0.4968 & -0.11 & 0.21 \\
\hline GM (left) & -0.23 & 0.2559 & -0.67 & 0.18 & 0.04 & 0.8223 & -0.30 & 0.37 & -0.10 & 0.4632 & -0.24 & 0.11 \\
\hline
\end{tabular}

Notes: Position A: position of lower limbs in $90^{\circ}$ of flexion in hip and knee joints - decreased anterior pelvic tilt. Position B: position of lower limbs with a slight flexion of hip and knee joints - intermediate pelvic position. Position C: supine position (lower limbs without flexion in hip and knee joints) - increased anterior pelvic tilt.

Abbreviations: PFM, pelvic floor muscle; Cl, confidence interval; AM, adductor magnus; RA, rectus abdominis; GM, gluteus maximus.

Table 6 Results of the multiple linear regression of the functional bioelectrical activity of PFM in positions A, B, and C

\begin{tabular}{|c|c|c|c|c|c|c|c|c|c|c|c|c|}
\hline \multirow{3}{*}{$\begin{array}{l}\text { Bioelectrical } \\
\text { activity of } \\
\text { muscle }\end{array}$} & \multicolumn{12}{|c|}{ Functional bioelectrical activity of PFM in position } \\
\hline & \multicolumn{4}{|l|}{$\mathbf{A}$} & \multicolumn{4}{|l|}{ B } & \multicolumn{4}{|l|}{ C } \\
\hline & $\beta$ & $P$-value & $-95 \% \mathrm{Cl}$ & $+95 \% \mathrm{Cl}$ & $\beta$ & $P$-value & $-95 \% \mathrm{Cl}$ & $+95 \% \mathrm{Cl}$ & $\beta$ & $P$-value & $-95 \% \mathrm{Cl}$ & $+95 \% \mathrm{Cl}$ \\
\hline AM (right) & 0.22 & 0.1695 & -0.74 & 4.10 & -0.14 & 0.4012 & -0.74 & 0.30 & -0.08 & 0.6426 & -1.44 & 0.90 \\
\hline AM (left) & 0.13 & 0.4774 & -0.85 & 1.79 & 0.20 & 0.2580 & -0.24 & 0.86 & 0.21 & 0.2255 & -0.47 & 1.96 \\
\hline RA (right) & 0.03 & 0.8829 & -3.16 & 3.66 & -0.04 & 0.7938 & -3.28 & 2.52 & -0.09 & 0.5356 & -1.72 & 0.91 \\
\hline RA (left) & 0.03 & 0.8689 & -3.98 & 4.70 & 0.11 & 0.5118 & -2.32 & 4.59 & -0.01 & 0.9550 & -3.32 & 3.14 \\
\hline GM (right) & -0.05 & 0.7931 & -1.03 & 0.79 & -0.09 & 0.7217 & -1.16 & 0.81 & 0.04 & 0.7805 & -0.82 & 1.08 \\
\hline GM (left) & -0.27 & 0.2013 & -1.90 & 0.41 & 0.05 & 0.8352 & -0.94 & 1.16 & -0.18 & 0.2213 & -1.50 & 0.36 \\
\hline
\end{tabular}

Notes: Position A: position of lower limbs in $90^{\circ}$ of flexion in hip and knee joints - decreased anterior pelvic tilt. Position B: position of lower limbs with a slight flexion of hip and knee joints - intermediate pelvic position. Position C: supine position (lower limbs without flexion in hip and knee joints) - increased anterior pelvic tilt.

Abbreviations: PFM, pelvic floor muscle; Cl, confidence interval; AM, adductor magnus; RA, rectus abdominis; GM, gluteus maximus. 
PFM EMG activity occurred in the horizontal position and when standing with the ankles in the dorsiflexion position (when the pelvis tilts anteriorly) than when standing with the ankles in the plantar flexion position. The results of Chen et $\mathrm{al}^{35}$ are similar to our observations as, in the supine position (C), in which the participants achieved the highest functional PFM activity, the pelvis tends to roll forward the most.

In the scientific literature, ${ }^{32-35,38,39}$ some authors highlight a close correlation and cross-functional connections between the pelvis, the PFM, and other structures of the area. Incorrect pelvis position can contribute to topographical changes in the position of the proximal part of the urethra and bladder neck with respect to the surrounding structures, including the urogenital diaphragm., ${ }^{7,40}$ The course of the urethra in healthy women is generally straightforward, and its curvature can be observed in the strong lift of the pelvic floor, with a large filling of the rectum, or lowering of the pelvic floor and bladder. When the pelvis orientation is correct, the urethra is directed obliquely downward and forward, almost vertically, which allows the free flow of urine during relaxation of the sphincter. ${ }^{41-45}$ The more perpendicular the course of the urethra with respect to the pelvic floor, the greater the closing force of its lumen is generated by the PFM. However, according to Capson et al, ${ }^{34}$ in the hypolordotic posture, the angle between the urethra and the PFM is greater than in a neutral or hyperlordotic posture, which does not explain, as discussed in this study, the higher sEMG activity achieved in an anterior pelvic tilt position.

The scientific literature also reports on the influence of synergist muscles on PFM. It is believed that muscles around the hip joint (especially, the AM and GM) may increase the activity of the PFM, ${ }^{46-51}$ while the abdominal muscles, by affecting the muscle corset of the trunk, can unweight the PFM.

In the current study, the most visible differences of the activity of the synergist muscles were observed within the AM. The lowest values of electrical potential (resting and functional) of these muscles were in the supine position. However, the highest sEMG values were observed in position $\mathrm{B}$, in which the feet were supported. The feet support in this position could elicit postural reactions. In positions $\mathrm{A}$ and $\mathrm{C}$, the feet did not have the support, which might result in lower sEMG activity of the AM muscles. It can also be assumed that the AM would therefore be strongly activated in the standing position. A significant relationship between the activation of the AM and the PFM was shown by Norton and Baker. ${ }^{52}$ They conducted a cough stress test in a standing position, standing with the legs crossed, and standing with the body inclined. The authors showed less urine leakage while standing with the legs crossed than while standing in a normal position $(P<0.01)$, which may show the strong effect of the AM muscles on PFM performance. Furthermore, Bø and Stien ${ }^{41}$ observed that the contraction of, eg, the adductor muscles, leads to the activation of the PFM.

Other muscles interacting with the pelvic floor are the GM and abdominal muscles. We did not observe any significant changes within RA in any of the positions. Sapsford et $\mathrm{al}^{53}$ noticed that during slump-supported sitting, the activity of the PFM was lower compared to unsupported sitting positions (which require greater muscle involvement). The authors postulated that particular abdominal exercises would activate the PFM. Similar to the AM, the resting and functional activities of the GM in the supine position were the lowest. The highest values of these muscles were observed in position $B$. Morin et $\mathrm{l}^{54}$ noticed that hip muscles, mainly the rotator and gluteal group, facilitate PFM activation.

PFM exercises are recommended as a first-line treatment of SUI. Although the differences in PFM activity in different positions are still controversial, a supine position seems to be the most suitable for assessing the function and mechanism of PFM, especially in women with SUI. ${ }^{37}$ In light of the abovementioned scientific reports and what is reported in this article, the relationship among PFM, synergist muscles and the pelvic tilt merits further investigation.

\section{Limitations}

The assessment of activity of only a certain synergistic muscles (RA, AM, GM) is a limitation of this study. The attempt to evaluate the other abdominal muscles would be very meaningful. In the literature, it is noted that the transverse abdominal muscle as well as external and internal oblique muscles play an important accessory functions in PFM performance. The decision on the assessment of selected muscles came out of the limitations of research equipment, which was able to evaluate simultaneously PFM and three pairs of other muscles.

Promising results of the study encourage to continue undertaken research. The new projects will take into account the results presented in this study as well as additional aspects that may also affect the increase in the bioelectrical activity of PFM. This study presents basic research. However, the evaluation of selected muscles in the tested positions in patients with pelvic floor insufficiency will be a continuation of the research conducted by the authors. 


\section{Conclusion}

In the study, we evaluated the relationship between the activity of PFM and various lower limb positions. The results showed that in the supine position, the PFM achieved the lowest resting activity and the highest functional activity. Therefore, the supine position can be recommended for the diagnosis and therapy of weakened PFM and SUI. In the assessed positions, we did not observe that the synergist muscles (AM, RA, GM) influence PFM activity. Thus, the obtained PFM activity may be treated as a result measured in isolated conditions. It seems, however, that other muscles, such as the transverse abdominal muscles and abdominal oblique muscles, play a great supporting role for the PFM, which will be investigated in further studies.

\section{Acknowledgment}

The project was funded by the National Science Centre, allocated on the basis of the decision number DEC-2011/03/N/ NZ7/00505.

\section{Disclosure}

The authors report no conflicts of interest in this work.

\section{References}

1. Menezes M, Pereira M, Hextall A. Predictors of female urinary incontinence at midlife and beyond. Maturitas. 2010;65(2):167-171.

2. Bø K. Pelvic floor muscle training in treatment of female stress urinary incontinence, pelvic organ prolapse and sexual dysfunction. World $J$ Urol. 2012;30(4):437-443.

3. Cody JD, Jacobs ML, Richardson K, Moehrer B, Hextall A. Oestrogen therapy for urinary incontinence in post-menopausal women. Cochrane Database Syst Rev. 2012;10:CD001405.

4. Schünke M, Schulte E, Schumacher U, et al. Prometeusz - atlas anatomii człowieka. T. 1, T. 1. Wrocław: MedPharm Polska; 2013.

5. Amaro JL, Moreira ECH, De Oliveira Orsi Gameiro M, Padovani CR. Pelvic floor muscle evaluation in incontinent patients. Int Urogynecol J Pelvic Floor Dysfunct. 2005;16(5):352-354.

6. Aukee P, Usenius J-P, Kirkinen P. An evaluation of pelvic floor anatomy and function by MRI. Eur J Obstet Gynecol Reprod Biol. 2004;112(1):84-88.

7. Bø K, editor. Evidence-Based Physical Therapy for the Pelvic Floor: Bridging Science and Clinical Practice. Edinburgh: Churchill Livingstone; 2008. Reprinted.

8. Berg JA, Larson CA, Pasvogel AE. Menopausal symptom perception and severity: results from a screening questionnaire. J Clin Nurs. 2008; 17(7):940-948.

9. Canderelli R, Leccesse LA, Miller NL, Unruh Davidson J. Benefits of hormone replacement therapy in postmenopausal women. $\mathrm{J} \mathrm{Am} \mathrm{Acad}$ Nurse Pract. 2007;19(12):635-641.

10. Dennerstein L, Dudley EC, Hopper JL, Guthrie JR, Burger HG. A prospective population-based study of menopausal symptoms. Obstet Gynecol. 2000;96(3):351-358.

11. Dimpfl T, Jaeger C, Mueller-Felber W, et al. Myogenic changes of the levator ani muscle in premenopausal women: the impact of vaginal delivery and age. Neurourol Urodyn. 1998;17(3):197-205.

12. Hsieh C-H, Su T-H, Chang S-T, Lin S-H, Lee M-C, Lee MY. Prevalence of and attitude toward urinary incontinence in postmenopausal women. Int J Gynaecol Obstet. 2008;100(2):171-174.
13. Halski T, Słupska L, Dymarek R, et al. Evaluation of bioelectrical activity of pelvic floor muscles and synergistic muscles depending on orientation of pelvis in menopausal women with symptoms of stress urinary incontinence: a preliminary observational study. Biomed Res Int. 2014; 2014:274938.

14. Basha ME, Chang S, Burrows LJ, et al. Effect of estrogen on molecular and functional characteristics of the rodent vaginal muscularis. $J$ Sex Med. 2013;10(5):1219-1230.

15. von Mühlen DG, Kritz-Silverstein D, Barrett-Connor E. A communitybased study of menopause symptoms and estrogen replacement in older women. Maturitas. 1995;22(2):71-78.

16. Zoubina EV, Mize AL, Alper RH, Smith PG. Acute and chronic estrogen supplementation decreases uterine sympathetic innervation in ovariectomized adult virgin rats. Histol Histopathol. 2001;16(4):989-996.

17. Hilde G, Stær-Jensen J, Siafarikas F, Ellström Engh M, Bø K. Postpartum pelvic floor muscle training and urinary incontinence: a randomized controlled trial. Obstet Gynecol. 2013;122(6):1231-1238.

18. Abdool Z, Shek KL, Dietz HP. The effect of levator avulsion on hiatal dimension and function. Am J Obstet Gynecol. 2009;201(1): 89.e1-e89.e5.

19. Dietz HP, Shek C. Levator avulsion and grading of pelvic floor muscle strength. Int Urogynecol J Pelvic Floor Dysfunct. 2008;19(5):633-636.

20. Guzmán Rojas R, Wong V, Shek KL, Dietz HP. Impact of levator trauma on pelvic floor muscle function. Int Urogynecol J. 2014;25(3): 375-380.

21. Bernstein IT. The pelvic floor muscles: muscle thickness in healthy and urinary-incontinent women measured by perineal ultrasonography with reference to the effect of pelvic floor training. Estrogen receptor studies. Neurourol Urodyn. 1997;16(4):237-275.

22. Fitzpatrick M, O'Herlihy $\mathrm{C}$. The effects of labour and delivery on the pelvic floor. Best Pract Res Clin Obstet Gynaecol. 2001;15(1):63-79.

23. Hilde G, Stær-Jensen J, Siafarikas F, Engh ME, Brækken IH, Bø K. Impact of childbirth and mode of delivery on vaginal resting pressure and on pelvic floor muscle strength and endurance. Am J Obstet Gynecol. 2013;208(1):50.e1-50.e7.

24. Botelho S, Pereira LC, Marques J, et al. Is there correlation between electromyography and digital palpation as means of measuring pelvic floor muscle contractility in nulliparous, pregnant, and postpartum women? Neurourol Urodyn. 2013;32(5):420-423.

25. Blondel B, Alexander S, Bjarnadóttir RI, et al. Variations in rates of severe perineal tears and episiotomies in 20 European countries: a study based on routine national data in Euro-Peristat Project. Acta Obstet Gynecol Scand. 2016;95(7):746-754.

26. Auchincloss C, McLean L. Does the presence of a vaginal probe alter pelvic floor muscle activation in young, continent women? J Electromyogr Kinesiol. 2012;22(6):1003-1009.

27. Glazer HI, Romanzi L, Polaneczky M. Pelvic floor muscle surface electromyography. Reliability and clinical predictive validity. J Reprod Med. 1999;44(9):779-782.

28. Duval K, Lam T, Sanderson D. The mechanical relationship between the rearfoot, pelvis and low-back. Gait Posture. 2010;32(4):637-640.

29. Betsch M, Schneppendahl J, Dor L, et al. Influence of foot positions on the spine and pelvis. Arthritis Care Res. 2011;63(12):1758-1765.

30. Bogusiewicz M, Rosińska-Bogusiewicz K, Drop A, Rechberger T. Anatomical variation of bony pelvis from the viewpoint of transobturator sling placement for stress urinary incontinence. Int Urogynecol J. 2011; 22(8):1005-1009.

31. Chen H-L, Lin Y-C, Chien W-J, Huang W-C, Lin H-Y, Chen P-L. The effect of ankle position on pelvic floor muscle contraction activity in women. J Urol. 2009;181(3):1217-1223.

32. Bø K, Lilleås F, Talseth $\mathrm{T}$, Hedland H. Dynamic MRI of the pelvic floor muscles in an upright sitting position. Neurourol Urodyn. 2001;20(2): 167-174.

33. Cerruto MA, Vedovi E, Mantovani W, D’Elia C, Artibani W. Effects of ankle position on pelvic floor muscle electromyographic activity in female stress urinary incontinence: preliminary results from a pilot study. Arch Ital Urol Androl. 2012;84(4):184-188. 
34. Capson AC, Nashed J, Mclean L. The role of lumbopelvic posture in pelvic floor muscle activation in continent women. J Electromyogr Kinesiol. 2011;21(1):166-177.

35. Chen C-H, Huang M-H, Chen T-W, Weng M-C, Lee C-L, Wang G-J. Relationship between ankle position and pelvic floor muscle activity in female stress urinary incontinence. Urology. 2005;66(2):288-292.

36. ANZCTR. Influence of pelvic orientation and synergistic muscle tone on bioelectrical activity of pelvic floor muscles in menopausal and postmenopausal women with or without urinary incontinence. Available from: https://www.anzctr.org.au/Trial/Registration/TrialReview. aspx?id=365132. Trial ID ACTRN12613001144707. Accessed November 24, 2016.

37. Bø K, Finckenhagen HB. Is there any difference in measurement of pelvic floor muscle strength in supine and standing position? Acta Obstet Gynecol Scand. 2003;82(12):1120-1124.

38. Gameiro MO, Miraglia L, Gameiro LFO, Padovani CR, Amaro JL. Pelvic floor muscle strength evaluation in different body positions in nulliparous healthy women and its correlation with sexual activity. Int Braz J Urol. 2013;39(6):847-852.

39. Workman JC, Docherty D, Parfrey KC, Behm DG. Influence of pelvis position on the activation of abdominal and hip flexor muscles. J Strength Cond Res. 2008;22(5):1563-1569.

40. Hung H-C, Hsiao S-M, Chih S-Y, Lin H-H, Tsauo J-Y. Effect of pelvicfloor muscle strengthening on bladder neck mobility: a clinical trial. Phys Ther. 2011;91(7):1030-1038.

41. Bø K, Stien R. Needle EMG registration of striated urethral wall and pelvic floor muscle activity patterns during cough, Valsalva, abdominal, hip adductor, and gluteal muscle contractions in nulliparous healthy females. Neurourol Urodyn. 1994;13(1):35-41.

42. Dietz HP, Shek KL. Levator function and voluntary augmentation of maximum urethral closure pressure. Int Urogynecol J. 2012; 23(8):1035-1040.

43. Lovegrove Jones RC, Peng Q, Stokes M, Humphrey VF, Payne C, Constantinou CE. Mechanisms of pelvic floor muscle function and the effect on the urethra during a cough. Eur Urol. 2010;57(6): 1101-1110.

44. McLean L, Varette K, Gentilcore-Saulnier E, Harvey M-A, Baker K, Sauerbrei E. Pelvic floor muscle training in women with stress urinary incontinence causes hypertrophy of the urethral sphincters and reduces bladder neck mobility during coughing. Neurourol Urodyn. 2013; 32(8):1096-1102.
45. Shafik A. A new concept of the anatomy of the anal sphincter mechanism and the physiology of defecation: mass contraction of the pelvic floor muscles. Int Urogynecol J Pelvic Floor Dysfunct. 1998;9(1):28-32.

46. Bø K, Sherburn M, Allen T. Transabdominal ultrasound measurement of pelvic floor muscle activity when activated directly or via a transversus abdominis muscle contraction. Neurourol Urodyn. 2003; 22(6):582-588.

47. Arab AM, Chehrehrazi M. The response of the abdominal muscles to pelvic floor muscle contraction in women with and without stress urinary incontinence using ultrasound imaging. Neurourol Urodyn. 2011; 30(1):117-120.

48. Arab AM, Behbahani RB, Lorestani L, Azari A. Assessment of pelvic floor muscle function in women with and without low back pain using transabdominal ultrasound. Man Ther. 2010;15(3):235-239.

49. Bø K, Mørkved S, Frawley H, Sherburn M. Evidence for benefit of transversus abdominis training alone or in combination with pelvic floor muscle training to treat female urinary incontinence: a systematic review. Neurourol Urodyn. 2009;28(5):368-373.

50. Soljanik I, Janssen U, May F, et al. Functional interactions between the fossa ischioanalis, levator ani and gluteus maximus muscles of the female pelvic floor: a prospective study in nulliparous women. Arch Gynecol Obstet. 2012;286(4):931-938.

51. Watanabe K, Katayama K, Ishida K, Akima H. Electromyographic analysis of hip adductor muscles during incremental fatiguing pedaling exercise. Eur J Appl Physiol. 2009;106(6):815-825.

52. Norton PA, Baker JE. Postural changes can reduce leakage in women with stress urinary incontinence. Obstet Gynecol. 1994;84(5):770-774.

53. Sapsford RR, Richardson CA, Maher CF, Hodges PW. Pelvic floor muscle activity in different sitting postures in continent and incontinent women. Arch Phys Med Rehabil. 2008;89(9):1741-1747.

54. Morin M, Dumoulin C, Bourbonnais D, Gravel D, Lemieux M. Co-activation of the pelvic floor muscles during contraction of the hip external rotators. Poster presented at: Annual Meeting of the International Continence Society; August 25-27th; 2004; Paris, France.
Clinical Interventions in Aging

\section{Publish your work in this journal}

Clinical Interventions in Aging is an international, peer-reviewed journal focusing on evidence-based reports on the value or lack thereof of treatments intended to prevent or delay the onset of maladaptive correlates of aging in human beings. This journal is indexed on PubMed Central, MedLine,

\section{Dovepress}

CAS, Scopus and the Elsevier Bibliographic databases. The manuscript management system is completely online and includes a very quick and fair peer-review system, which is all easy to use. Visit http://www.dovepress. com/testimonials.php to read real quotes from published authors. 